\title{
In silico and in vitro Approach to Identify Memory Enhancers from Sida rhombifolia L.
}

\author{
Laxmi Pattanashetti ${ }^{1} *$, BM Patil', Harsha V Hegde ${ }^{2}$ \\ 'Department of Pharmacology, KLE Academy of Higher Education and Research, College of Pharmacy, Belagavi, Karnataka, INDIA. \\ 2Department of Ethnomedicine, Indian Council of Medical Research - National Institute of Traditional Medicine, Belagavi, Karnataka, INDIA.
}

\begin{abstract}
Background: Sida rhombifolia L. is a well documented Ayurvedic medicine for the management of neurodegenerative diseases and to enhance cognitive function. Researchers demonstrated its activities under various animal model/s, but lack the probable molecular mechanism in the treatment of Alzheimer's disease. Current study was aimed to identify the acetylcholinesterase (AChE) inhibitory potency of phytocompounds and enriched fractions from S.rhombifolia using in vitro and network pharmacology approaches. Methods: Phytocompounds were retrieved from phytochemical databases, scientific reports and quired for druggability. Protein targets were predicted using BindingDB $(p \geq 0.7)$. STRING database and KEGG pathway were utilized to perform gene set enrichment analysis and to identify the probable pathways modulated by the phytocompounds. Cytoscape v3.6.1 was used to construct a target-compound-pathway network. Docking was performed by PyRx 0.8v. Enriched fractions of S. rhombifolia were tested for in vitro AChE inhibitory potency using the AChE enzyme. Results: Among 35 compounds, 26 compounds showed positive drug likeness property. Out of 26 compounds, 9 compounds i.e. 2D-hydroxyecdysone, ecdysone, pterosterone-3-O- $\beta$-D-glucopyranoside, acacetin, kaempferol, sanguinine, vascicine, vasicinol, vasicinone were
\end{abstract}

predicted to target $\mathrm{AChE}$ and other 9 therapeutic targets involved in Alzheimer's disease (AD). Acacetin scored lowest binding energy with AChE $(-8.9 \mathrm{kcal} / \mathrm{mol})$. Among the selected enriched fractions, hexane fraction pertains highest AChE inhibition $\left(\mathrm{IC}_{50} 12.87 \mu \mathrm{g} / \mathrm{ml}\right)$ compared to clinical approved drug Donepezil $\left(I C_{50} 2.92 \mu \mathrm{g} / \mathrm{ml}\right)$. Conclusion: The role of S.rhombifolia for the management of $A D$ could be attributed due to the major effect of 2D-hydroxyecdysone, ecdysone, pterosterone-3-O- $\beta$-Dglucopyranoside, acacetin, kaempferol, sanguinine, vascicine, vasicinol, vasicinone on AChEand their action on multiple protein molecules associated with $A D$ pathogenesis.

Key words: Alzheimer's disease, Acacetin, Acetylcholinesterase, In silico docking, Network pharmacology, Sida rhombifolia, Sangunine.

\section{Correspondence}

Mrs. Laxmi Pattanashetti,

Department of Pharmacology, KLE Academy of Higher Education and Research, College of Pharmacy, Belagavi, Karnataka, INDIA.

Email id: pattanashetti.laxmi67@gmail.com

DOI: 10.5530/jyp.2021.13.90

\section{INTRODUCTION}

The most commonly known neurodegenerative disorder with the agerelated risk factor is Alzheimer's disease (AD). The specific regions of brain parts demonstrate loss of synaptic connections, including accumulation of abnormal proteins such as extracellular amyloid plaque, intracellular neurofibrillary tangles. ${ }^{1}$ Another important characterized feature is the abnormal alteration of Acetylcholine (ACh) neurotransmission; due to lower amount of choline acetyltransferase and decreased ACh released leads to loss of cholinergic functions in neocortex and hippocampus regions of the brain and this phenomenon is common in AD patients. ${ }^{2}$ As per Delphi study " 24 million people suffering from dementia in 2001 worldwide and this Figure was estimated to double in 2020 and quadruple in 2040". $\mathrm{AD}$ generates difficulty in the management of effective treatment due to its multiple mechanisms involved in pathogenesis.

Currently, US-FDA-approved drugs are cholinesterase inhibitors (Donepezil, Rivastigmine, Galantamine) and NMDA receptor modulator (Memantine) as first-line treatments but, these present limitations for the long term treatment due to unavoidable side effects mainly caused by peripheral cholinergic system activation. $\cdot{ }^{4,5}$ Considerably, it is essential to explore new, effective, and safe drugs. Mankind has advantages from ancient days by the plants, which are an abundant source of phytoconstituents considered as a novel in the therapy of many ailments. ${ }^{6}$ Because there is "eighty percent of the world population relies on medicinal plants to meet their primary health care" as per World Health Organization (WHO) reports. ${ }^{7}$

The genus Sida. L belongs to the family Malvaceae is well documented in Ayurveda; ancient Indian system of medicine and 17 species are reported to occur in India; used traditionally in Rasayana to treat various ailments including degenerative and musculoskeletal disease. Perennial plant S. rhombifolia L.is known as 'Mahabala' reported as an anti-inflammatory, anti-arthritic and hepatoprotective effect. ${ }^{8}$ The hot aqueous extracts of dried leaf and root of the S. rhombifolia are used to treat nervous diseases, heart diseases, burning sensation of the body and as an aphrodisiac and tonic. ${ }^{9}$ The recent report claim the effect of S. rhombifolia extract to decrease the beta-amyloid accumulation in rat brain. ${ }^{10}$

Presently drug discovery emerges advancement in the treatment of complex diseases like $\mathrm{AD}$ with the concept of multi-compound drug therapy using herbs targeting cluster of disease-associated proteins and pathways. Understanding of network pharmacology approach in a per view of the "Lock and Key" model to design ligand that acts on specific targets provides new insights to elucidate the multi-scale mechanisms of action of herbs. Moreover, it is well explained that the master key could "open multiple locks" by targeting many proteins instead of preferring a single target. ${ }^{11}$

However, there are no scientific reports to show the mechanism of S. rhombifolia fractions for the management of cognitive dysfunction

This is an open access article distributed under the terms of the Creative Commons Attribution-NonCommercial-ShareAlike 4.0 License, which allows others to remix, tweak, and build upon the work non-commercially, as long as the author is credited and the new creations are licensed under the identical terms. 
and $\mathrm{AD}$. Hence, this work demonstrates to decipher the pathogenic processes, functions, and pathways modulated by the key bioactive phytocompounds against the progression of cognitive dysfunction and $\mathrm{AD}$ via compound-gene pathway enrichment, network pharmacology, and in silico docking study. Futher interlink the potent fraction from S. rhombifolia responsible for the acetylcholinesterase inhibition by an in vitro method.

\section{MATERIALS AND METHODS}

\section{Mining and drug-likeness property of phytocompounds}

Phytoconstituents from Sida rhombifolia (SR) were retrieved from herbs databases i.e. ChEBI, Dr. Duke's database, and earlier scientific reports ${ }^{12-15}$ using a keyword "Sida rhombifolia". The information such as molecular weight, molecular formula, canonical SMILES, number of hydrogen bond donors, and acceptors of each compound was retrieved from the PubChem chemical database (https://pubchem.ncbi.nlm.nih. gov/). Based on "Lipinski's Rule of Five" model in MolSoft (https:// molsoft.com/) the drug-likeness score for each compound was predicted. ${ }^{16}$

\section{Target identification}

TTD (Therapeutic Target Database, https://db.idrblab.org/ttd/) was utilized to collect $\mathrm{AD}$-related targets; alongside each protein, gene ID was collected from UniProt (https://www.uniprot.org/) protein database with standard reference to "Homo sapiens" species. Initially, canonical SMILES of phytocompounds having druggable characteristics were submitted into "Find My Compound Targets" of Binding DB web server for target identification at the percentile score of $\geq 70 \%$. After the target prediction, compounds targeting only approved therapeutic targets involved in the $\mathrm{AD}$ which are deposited in the TTD were retrieved. ${ }^{17}$ The probable targets modulated by the phytocompounds were shown in Supplementary Table 1 .

\section{Gene set enrichment and network analysis}

The target/protein(s) responsible for the development of pathogenesis in $\mathrm{AD}$ which is modulated by the compounds was speculated by using STRING (https://string-db.org/). The enriched pathways data were collected from the Kyoto Encyclopedia of Genes (KEGG) pathway. The compound-gene-pathway network was constructed using Cytoscape version 3.6.1. The network was analyzed using the command "Network Analyzer" and the network was treated as direct. Interaction among the compound and gene was explicated by the edge count. ${ }^{18}$

\section{Docking study}

A docking study was performed using AutoDock Vina. Each compound $3 \mathrm{D}$ structure were retrieved from the PubChem database in .sdf format. Compounds were converted into .pdb format using Discovery Studio 2019. Protein molecules $x$-ray crystallographic structures were retrieved from the RCSB PDB in.pdb format. Compounds with their respective proteins were imported into PyRx $0.8 \mathrm{v}$ software and converted into .pdbqt format. Grid box was default and exhaustiveness was kept for 8 . The protein-ligand complex having the lowest BE was visualized in DSV v2019. ${ }^{19}$

\section{Plant collection and authentication}

Whole plant S. rhombifolia L. was collected from Botanical Garden, Karnataka University, Dharwad, Karnataka, India. Authenticated by a botanist from ICMR- National Institute of Traditional Medicine, Belagavi. The herbarium voucher specimen No. RMRC-1399 was deposited at ICMR-NITM, Belagavi for future reference.

\section{Extraction and Fractionation of S. rhombifolia}

Drugs and Chemicals used for the study were of analytical grade and procured from (Himedia, India). Dry powder of S. rhombifolia (500gms) was subjected to cold maceration to extract thermolabile constituents if any with $70 \% \mathrm{v} / \mathrm{v}$ ethanol for $24 \mathrm{hr}$. The extract was filtered, and the marc was further subjected to soxhlation ( $95 \% \mathrm{v} / \mathrm{v}$ ethanol). Filtrates of both maceration and soxhlation were combined and concentrated using a rotary evaporator (IKA RV 10) at $40^{\circ} \mathrm{C}$ under reduced pressure.

The total extract was collected. Later, fractionation of S. rhombifolia extract was carried out as per the method described by Cos $\mathrm{P}$ et al. ${ }^{20}$ with minor modifications.

\section{In vitro estimation of Acetylcholinesterase enzyme by Ellman's method}

AChE activity was measured by using a spectrophotometer based on Ellman's method. ${ }^{21}$ The enzyme hydrolyzes the substrate acetylthiocholine resulting in the product thiocholine which reacts with Ellman's reagent (DTNB) to produce 2-nitrobenzoate-5 mercaptothiocholine and 5-thio2- nitrobenzoate which can be detected at $412 \mathrm{~nm}$.

Test tube containing $1710 \mu \mathrm{L}$ of $50 \mathrm{mM}$ Tris- $\mathrm{HCl}$ buffer $\mathrm{pH} 8.0$ and $250 \mu \mathrm{L}$ of crude fractions namely petroleum ether, hexane, chloroform, ethanol and aqueous fractions at the concentrations of $10-160 \mu \mathrm{g} / \mathrm{mL}$, $10 \mu \mathrm{L} 6.67 \mathrm{UmL}^{-1} \mathrm{AChE}$ and $20 \mu \mathrm{L}$ of $10 \mathrm{mM}$ of DTNB (5,5'-dithio-bis [2- nitrobenzoic acid]) in buffer was added. Positive control namely Donepezil hydrochloride $(10-160 \mu \mathrm{g} / \mathrm{ml})$ (Sigma-Aldrich, USA) were prepared in serial concentration as same as test extract by dissolving in $50 \mathrm{mM}$ Tris- $\mathrm{HCl}$ buffer $\mathrm{pH}$ 8.0. The mixture was incubated for $15 \mathrm{~min}$ at $37^{\circ} \mathrm{C}$. Then, $10 \mu \mathrm{L}$ of acetylthiocholine iodide $(200 \mathrm{mM})$ in buffer was added to the mixture and the absorbance was measured at $412 \mathrm{~nm}$ every $10 \mathrm{sec}$ for $3 \mathrm{~min}$, for a blank with buffer instead of enzyme solution was used. The enzyme inhibition (\%) was calculated from the rate of absorbance change with time $(\mathrm{V}=\mathrm{Abs} / \Delta \mathrm{t})$.

\section{Statistical Analysis}

Values were expressed as Mean \pm SEM, $p<0.001$ was considered as statistically significant.

\section{RESULTS}

Mining and drug-likeness property of phytocompounds and targets prediction

Thirty-five phytocompounds from the S. rhombifolia were identified from the phytochemical interaction database, Dr. Duke's database, Chemical Entities of Biological Interest (ChEBI), and scientific reports. Among 35 compounds, 26 compounds showed a positive drug-likeness score, and 2D-Hydroxyecdysone scored highest i.e. 1.39 (Table 1). Among 26 compounds, 23 compounds were predicted to target 167 protein molecules and 3 compounds failed to predict the targets due to no structural similarity in the database. Further, the peer-interpretation identified 9 compounds to target 10 therapeutic protein molecules associated with $\mathrm{AD}$ (Table 2).

\section{Gene set enrichment and network analysis}

The gene set enrichment analysis showed 18 molecular pathways modulated by the 9 phytocompounds. Among them, 7 pathways were potentially involved in AD pathogenesis i.e. Serotonergic synapse, Inflammatory mediator regulation of TRP channels, Neuroactive ligandreceptor interaction, Calcium signaling pathway, Gap junction, Cholinergic synapse, and Alzheimer's disease (Table 3). The network analysis showed acacetin, 2D-hydroxyecdysone, ecdysone, pterosterone-3-O- $\beta$-Dglucopyranoside, and kaempferol, to score highest edge count and these compounds were identified as Flavonoids and Steroids. Sanguinine, 
Table 1: Druglikeness property of phytocompounds.

\begin{tabular}{|c|c|c|c|c|c|c|c|}
\hline Compounds & PubChem CID & $\begin{array}{l}\text { Molecular } \\
\text { Formula }\end{array}$ & $\begin{array}{c}\text { Molecular } \\
\text { Weight }(\mathrm{g} / \mathrm{mol})\end{array}$ & HBD & HBA & Log $P$ & DLS \\
\hline 2D-Hydroxyecdysone & 9912297 & $\mathrm{C}_{27} \mathrm{H}_{44} \mathrm{O}_{6}$ & 464.60 & 5 & 6 & 1.81 & 1.39 \\
\hline Acacetin & 5280442 & $\mathrm{C}_{16} \mathrm{H}_{12} \mathrm{O}_{5}$ & 284.26 & 2 & 5 & 3.74 & 0.2 \\
\hline Ecdysone & 19212 & $\mathrm{C}_{27} \mathrm{H}_{44} \mathrm{O}_{6}$ & 464.6 & 5 & 6 & 0.92 & 1.06 \\
\hline Kaempferol & 5280863 & $\mathrm{C}_{15} \mathrm{H}_{10} \mathrm{O}_{6}$ & 286.24 & 4 & 6 & 1.61 & 0.5 \\
\hline Pterosterone-3-O- $\beta$-D-Glucopyranoside & 441836 & $\mathrm{C}_{27} \mathrm{H}_{44} \mathrm{O}_{7}$ & 480.6 & 6 & 7 & 0.74 & 1.1 \\
\hline Sanguinine & 443722 & $\mathrm{C}_{16} \mathrm{H}_{19} \mathrm{NO}_{3}$ & 273.33 & 2 & 4 & 1.09 & 0.77 \\
\hline Vascicine & 72610 & $\mathrm{C}_{11} \mathrm{H}_{12} \mathrm{~N}_{2} \mathrm{O}$ & 188.23 & 1 & 2 & 1.08 & 0.33 \\
\hline Vasicinol & 442934 & $\mathrm{C}_{11} \mathrm{H}_{12} \mathrm{~N}_{2} \mathrm{O}_{2}$ & 204.22 & 2 & 3 & 0.62 & 0.61 \\
\hline Vasicinone & 442935 & $\mathrm{C}_{11} \mathrm{H}_{10} \mathrm{~N}_{2} \mathrm{O}_{2}$ & 202.21 & 1 & 3 & 0.35 & 0.38 \\
\hline
\end{tabular}

HBD Hydrogen Bond Donor; HBA Hydrogen Bond Acceptor; LogP; Partition Co-efficient; DLS Druglikeness score

Table 2: Probable targets involved in AD modulated by phytocompounds.

\begin{tabular}{ccc}
\hline Compound & Compound type & Gene ID (compound - target probability score) \\
\hline 2D-Hydroxyecdysone & Steroid & HTR2A (0.73), HTR2C (0.73), ACHE (0.7), BACE1 (0.76), BCHE (0.98) \\
Acacetin & Flavonoid & ACHE (0.7), ADORA2A (0.84), MAOA (0.84), MAOB (1.0), APP (0.79), BACE1 (0.7), BCHE (0.7) \\
Ecdysone & Steroid & HTR2A (0.71), HTR2C (0.71), ACHE (0.7), BACE1 (0.74), BCHE (0.7) 1 \\
Kaempferol & Flavonoid & ACHE (0.7), ADORA2A (0.97), MAOA (0.97), MAOB (0.86), BACE1 (0.7) \\
Pterosterone-3-O- $\beta$-D-Glucopyranoside & Steroid & HTR2A (0.7), HTR2C (0.7), ACHE (0.7), BACE1 (0.73), BCHE (0.7) \\
Sanguinine & Alkaloid & ACHE (0.98), CHRM1 (0.7), BCHE (0.98) \\
Vascicine & Alkaloid & ACHE (0.7), BCHE (0.7) \\
Vasicinol & Alkaloid & ACHE (0.76), BCHE (0.76) \\
Vasicinone & Alkaloid & ACHE (0.7), BCHE (0.71) \\
\hline
\end{tabular}

Table 3: Enrichment analysis of protein targets involved in AD.

\begin{tabular}{lcccc}
\hline KEGG ID & Pathway description & Gene count & False Discovery Rate & Protein targets within the network \\
\hline has04726 & Serotonergic synapse & 5 & $3.96 \mathrm{E}-08$ & APP, HTR2A, HTR2C, MAOA, MAOB \\
hsa04750 & Inflammatory mediator regulation of TRP channels & 2 & 0.0016 & HTR2A, HTR2C \\
hsa04080 & Neuroactive ligand-receptor interaction & 3 & 0.00082 & CHRM1, HTR2A, HTR2C \\
hsa04020 & Calcium signaling pathway & 3 & 0.00054 & CHRM1, HTR2A, HTR2C \\
hsa04540 & Gap junction & 2 & 0.0016 & HTR2A, HTR2C \\
hsa04725 & Cholinergic synapse & 3 & 0.0022 & ACHE, BCHE, CHRM1 \\
hsa04728 & Dopaminergic synapse & 2 & 0.0027 & MAOA, MAOB \\
hsa05010 & Alzheimer's disease & 2 & 0.0041 & APP, BACE1 \\
\hline
\end{tabular}

Vascicine, Vasicinol, and Vasicinone scored lowest edge count and these compounds were identified as Alkaloids, predicted to target only AChE and BChE (Figure 1 and Figure 2).

\section{Docking study}

Acacetin scored lowest BE with ACHE $(-8.9 \mathrm{kcal} / \mathrm{mol})$ by forming one hydrogen bond i.e. Thr124; with ADORA2A (-7.9kcal/mol) via one bond Glu169; with MAOA $(-8.5 \mathrm{kcal} / \mathrm{mol})$ via two bonds i.e. Glu329, and Arg172; with MAOB (-10.4) via 5 bonds i.e. Met436, Arg42, Ser15, Gly16, and Arg36; with APP (-6.4) via 3 bonds i.e. Ala9, Glu7, and Phr23. Kaempferol scored lowest BE with BACE1 $(-8.2 \mathrm{kcal} / \mathrm{mol})$ via 4 bonds i.e. Thr72, Thr72, Thr231, and Tyr198. Pterosterone-3-O- $\beta$-DGlucopyranoside scored lowed BE with HTR2A $(-8.1 \mathrm{kcal} / \mathrm{mol})$ via 4 bonds i.e. Arg173, Thr109, Thr109, and Asp172. Sanguinine OH group scored lowest BE with CHRM1 $(-7.9 \mathrm{kcal} / \mathrm{mol})$ via one bond i.e. Tyr106. Pterosterone-3-O- $\beta$-D-Glucopyranosidescored with BCHE $(-9.5 \mathrm{kcal} / \mathrm{mol})$ via 2 bonds i.e. Pro285 and Tyr440. However, Sanguinine, Vascicine, Vasicinol, and Vasicinone were also showed the best affinity with AChE and BChE via forming hydrogen bonds with amino acid residues. The probable score, binding energy, and hydrogen bond interaction of ligands with their respective targets were summarized (Table 4).

\section{In vitro AChE inhibition}

The preliminary phytochemical investigation identified the presence of flavonoids, saponins, alkaloids, tannins, steroids, and polyphenols in a hydroalcoholic extract of the whole plant of S.rhombifolia. Similarly, the phytoconstituents reported in fractions were summarized in Table 5 as per earlier reports. ${ }^{22-25}$ 


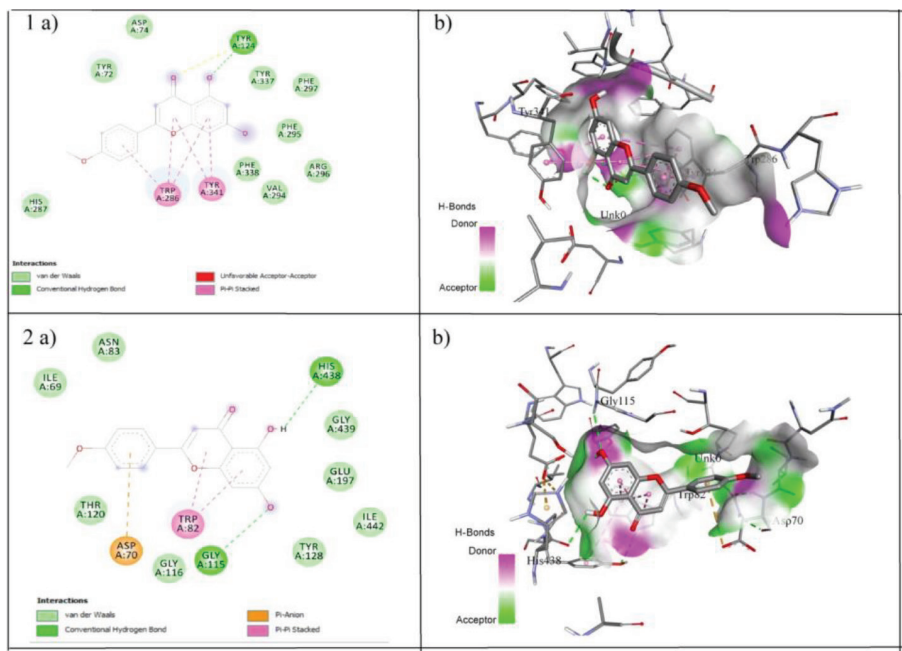

Figure 1: Network representation of the interaction of Phytocompoundstarget proteins-pathways.

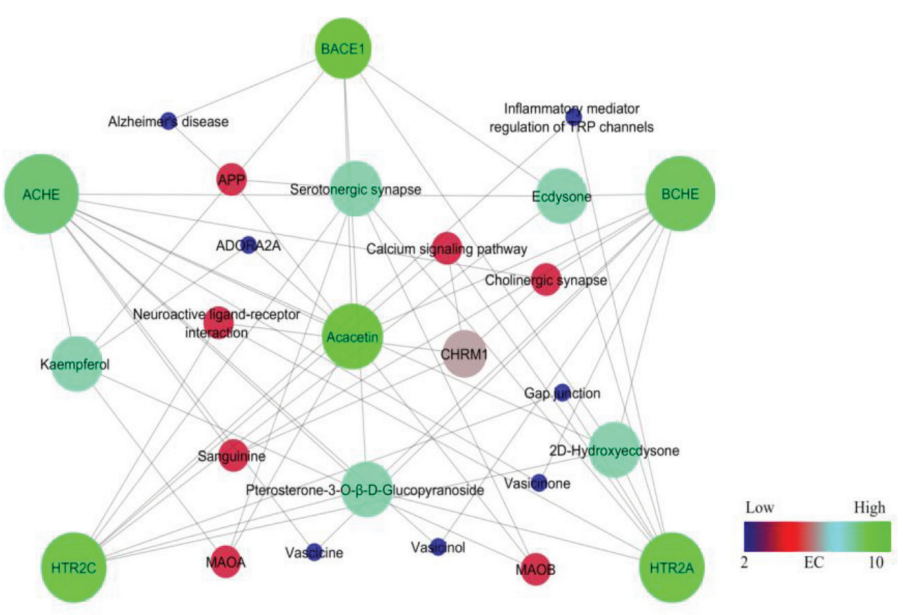

Figure 2: Binding analysis of Acacetin with $\mathrm{AChE}$ and $\mathrm{BChE}$. 1) Interaction of Acacetin with $A C h E$ a) $2 D$ representation b) Acacetin within $A C h E$ binding pocket 2) Interaction of Acacetin with $B C h E$ a) $2 D$ representation b) Acacetin within $\mathrm{BChE}$ binding pocket

The hexane fraction reported the presence of terpenoids, steroids, phytosterols; Ethanol fraction showed the presence of alkaloids, terpenoids, flavonoids, saponins, steroids; Aqueous fraction showed the presene of alkaloids, flavonoids, saponins; Chloroform fractions reported the presence of alkaloids, phenols; Pet ether solvent extracted terpenoids, fixed oil and fats from S. rhombifolia.

potentially inhibited the Acetylcholinesterase enzyme; Hexane fraction> Ethanol fraction $>$ Aqueous fraction $>$ Chloroform fraction $>$ Pet ether fraction with $\mathrm{IC}_{50}$ value at $12.87<18.96<20.75<30.47<41.95(\mu \mathrm{g} / \mathrm{ml})$ respectively. The Hexane fraction was found to show prominent $\mathrm{AChE}$ inhibitory activity which was compared to clinically approved molecule Donepezil $-2 \mu \mathrm{g} / \mathrm{ml}$ (Table 5).

\section{DISCUSSION}

The current study dealt to reveal the effect of S. rhombifolia in the treatment of $\mathrm{AD}$ by network pharmacology coupled with docking studies further, correlated with in vitro AChE inhibition assay to assure modulation of hallmark in $\mathrm{AD}$ by S. rhombifolia enriched fractions. The network phar- macology analysis was carried out to known the molecular mechanism of action and pharmacological basis of S. rhombifolia with specific proteins and their relationship with disease-modifying capability. Traditional herbs are the source of new drug discovery hence, utilization of multiple compounds containing herbs having a traditional claim against particular disease with minimal side effects via polypharmacology and bioinformatics approaches could be a new treatment strategy, supports the scientific validation of herbal medicines. ${ }^{26}$ Polypharmacology and bioinformatics deal with the effect of drugs on multiple protein targets modulating disease pathways. ${ }^{27}$

Initially, phytocompounds druggable characteristics were predicted and compounds having drug-like properties were utilized for further analysis. We predicted probable targets of each phytocompounds having a drug-like property using Binding DB and compounds only modulating therapeutic targets associated with $\mathrm{AD}$ at the probable score of $\geq 0.7$ were separated, and gene set pathways enrichment and network analysis were performed. Target prediction phased with the known structures to modulate biological activity by its probable protein targets by ligand as agonists or antagonists, ${ }^{28}$ considering pathological hallmarks of $\mathrm{AD}$ includes a variety of signaling pathways abnormalities along with dysfunction of $\mathrm{G}$ protein-mediated adenylate cyclase signaling unit. ${ }^{29}$ Current finding reports that the phytocompounds of S. rhombifolia targets G-Protein belonging receptors such as CHRM1, CHRM3, and HTR2A as well as production of amyloid precursor protein (APP), beta-amyloid (A $\beta$ ) signaling cascade, and $\mathrm{A} \beta$ - degradation. This is supported by Liu et al. ${ }^{30}$ reports suggesting that $\mathrm{G}$-protein serves as a therapeutic key for $\mathrm{AD}$. The probable target proteins modulated by the $S$. rhombifolia phytochemicals were subjected to gene set enrichment analysis to identify the pathways modulated by the compounds. We identified 9 compounds to modulate 10 therapeutic protein targets associate with $\mathrm{AD}$ i.e. Amyloid Precursor Protein (APP), 5-hydroxytryptamine receptor 2A (HTR2A), 5-hydroxytryptamine receptor 2C (HTR2C), Cholinergic Muscarinic 1 (CHRM1), Acetylcholinesterase (AChE), Butyrylcholinesterase (BChE), Amine oxidase [flavin-containing] A (MAOA), Amine oxidase [flavin-containing] $\mathrm{B}$ (MAOB), and Beta-secretase 1 (BACE1). These compounds were recognized as steroids, flavonoids, and alkaloids. Further, Serotonergic synapse, Inflammatory mediator regulation of TRP channels, Neuroactive ligand-receptor interaction, Calcium signaling pathway, Gap junction, Cholinergic synapse were identified as an enriched pathways in $\mathrm{AD}$ pathogenesis. Interestingly, these pathways were identified as G proteinmediated pathways.

Serotonin neuronal loss is involved in cognitive mechanisms such as short and long-term memory alongside this also regulates and co-localizes with cholinergic, GABAergic, glutamatergic neurons. ${ }^{31}$ Transient Receptor Potential Ankyrin 1 (TRPA1) channel considered as a "promiscuous" receptor expressed in many regions of the hippocampus including in astrocytes which plays a major role in intracellular calcium level and activation of this channel by free radicals or inflammatory mediator leads to several disruptive changes in the brain. ${ }^{32}$ In the current study, three-hit druggable steroidal molecules i.e. 2D-Hydroxyecdysone, Ecdysone, and Pterosterone-3-O- $\beta$-D-Glucopyranoside from S. rhombifolia were predicted to interact with the HTR2A and HTR2C protein targets, which are directly linked with TRPA1 and serotonergic synaptic pathways. Predominantly, these compounds are also predicted to interact with AChE, BChE, and BACE1.

Disruption of $\mathrm{Ca}^{2+}$ and its homeostasis is ubiquitously involved to induce synaptic deficits which promotes accumulation of $A \beta$ plaques and neurofibrillary tangles. ${ }^{33}$ Another hallmark of $\mathrm{AD}$ is a phenotypic change in microglia and astrocytes occurring in gliosis is another hallmark in $\mathrm{AD}$, this response is interlinked with alteration in function and protein expressions forming gap junction channels are 
Table 4: Affinity of phytocompounds with their respective targets.

\begin{tabular}{|c|c|c|c|c|}
\hline Target name & PDB ID & Compound & $\begin{array}{c}\text { BE } \\
\text { (kcal/mol) }\end{array}$ & HBI (amino acid....ligand) \\
\hline \multirow{3}{*}{$\begin{array}{l}\text { 5-hydroxytryptamine receptor } 2 \mathrm{~A} \\
\text { (HTR2A) }\end{array}$} & \multirow[t]{3}{*}{6 А94 } & 2D-Hydroxyecdysone & -7.7 & 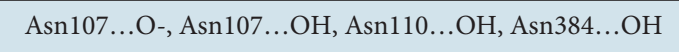 \\
\hline & & Ecdysone & -8.0 & 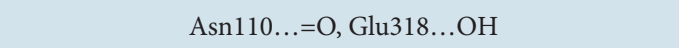 \\
\hline & & $\begin{array}{l}\text { Pterosterone-3-O- } \beta \text {-D- } \\
\text { Glucopyranoside }\end{array}$ & -8.1 & $\begin{array}{c}\operatorname{Arg} 173 \ldots=\mathrm{O}, \operatorname{Thr} 109 \ldots \mathrm{OH}, \mathrm{Thr} 109 \ldots=\mathrm{O}, \mathrm{Asp} 172 \ldots \mathrm{OH} \\
\text { His183 } \ldots \text { OH }\end{array}$ \\
\hline \multirow[t]{9}{*}{ Acetylcholinesterase (AChE) } & \multirow[t]{9}{*}{$4 \mathrm{PQE}$} & 2D-Hydroxyecdysone & -7.4 & 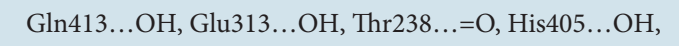 \\
\hline & & Acacetin & -8.9 & Thr124...O- \\
\hline & & Ecdysone & -7.4 & Asn233... OH \\
\hline & & Kaempferol & -8.5 & Ser293...OH \\
\hline & & $\begin{array}{l}\text { Pterosterone-3-O- } \beta \text {-D- } \\
\text { Glucopyranoside }\end{array}$ & -8.2 & 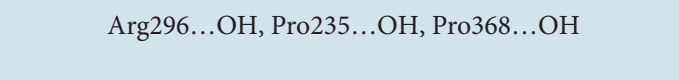 \\
\hline & & Sanguinine & -7.8 & Ser293...OH \\
\hline & & Vascicine & -7.9 & Thr83...H \\
\hline & & Vasicinol & -8.2 & Nil \\
\hline & & Vasicinone & -8.5 & 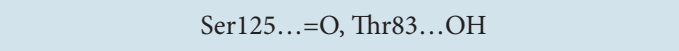 \\
\hline \multirow[t]{2}{*}{ Adenosine Receptors A2a (ADORA2A) } & \multirow[t]{2}{*}{$3 \mathrm{UZA}$} & Acacetin & -7.9 & Glu169...OH \\
\hline & & Kaempferol & -7.7 & Thr227...OH, Asn39 .. =O \\
\hline \multirow{2}{*}{$\begin{array}{c}\text { Amine oxidase [flavin-containing] } \\
\text { A (MAOA) }\end{array}$} & \multirow[t]{2}{*}{$2 Z 5 X$} & Acacetin & -8.5 & Glu329...OH, Arg172...O- \\
\hline & & Kaempferol & -8.2 & 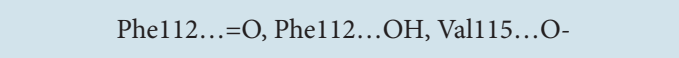 \\
\hline \multirow[t]{2}{*}{$\begin{array}{l}\text { Amine oxidase [flavin-containing] } \\
\text { B (MAOB) }\end{array}$} & \multirow[t]{2}{*}{ 1OJD } & Acacetin & -10.4 & 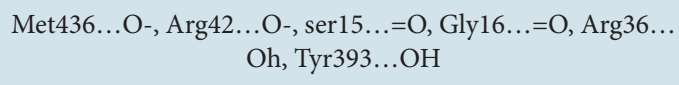 \\
\hline & & Kaempferol & -9.0 & 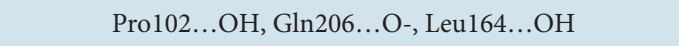 \\
\hline \multirow[t]{5}{*}{ Beta-secretase 1 (BACE1) } & \multirow[t]{5}{*}{$3 \mathrm{UQU}$} & 2D-Hydroxyecdysone & -6.6 & Gly11...OH, Glu310...O- \\
\hline & & Acacetin & -8.0 & $\operatorname{Th} 231 \ldots=\mathrm{O}, \mathrm{Th} 72 \ldots=\mathrm{O}$ \\
\hline & & Ecdysone & -6.9 & Gly90...OH \\
\hline & & Kaempferol & -8.2 & 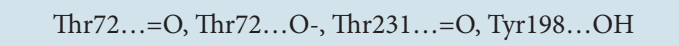 \\
\hline & & $\begin{array}{l}\text { Pterosterone-3-O- } \beta \text {-D- } \\
\text { Glucopyranoside }\end{array}$ & -6.8 & 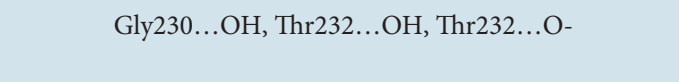 \\
\hline \multirow[t]{8}{*}{ Butyrylcholinesterase (BChE) } & \multirow[t]{8}{*}{ 4TPK } & 2D-Hydroxyecdysone & -8.9 & 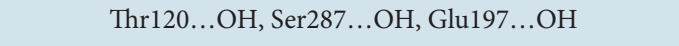 \\
\hline & & Acacetin & -9.2 & His $438 \ldots \mathrm{OH}, \mathrm{Gly} 115 \ldots \mathrm{O}-$ \\
\hline & & Ecdysone & -8.7 & Pro285...OH \\
\hline & & $\begin{array}{l}\text { Pterosterone-3-O- } \beta \text {-D- } \\
\text { Glucopyranoside }\end{array}$ & -9.5 & Pro $285 \ldots$ Oh, Tyr $440 \ldots \mathrm{OH}$ \\
\hline & & Sanguinine & -8.7 & His438...OH, Glu197...OH, Ser198_..OH \\
\hline & & Vascicine & -7.8 & His $438 \ldots \mathrm{NH}$, Tyr $440 \ldots \mathrm{OH}$ \\
\hline & & Vasicinol & -7.9 & His $438 \ldots . \mathrm{OH}, \operatorname{Trp} 82 \ldots \mathrm{O}-$ \\
\hline & & Vasicinone & -8.1 & Trp82...O-, His438...NH \\
\hline Cholinergic, muscarinic 1 (CHRM1) & $5 \mathrm{CXV}$ & Sanguinine & -7.9 & Tyr106...OH \\
\hline
\end{tabular}

PDB Protein Data Bank; BE Binding Energy; HBI Hydrogen bond Interaction

majorly connexins(Cxs). Amyloid $\beta$ having the most reactive astrocytes regions were found to have increased Cxs expression. ${ }^{34,35}$ APP undergoes proteolysis through BACE1 which generates $A \beta$. Current research focuses on germline deletion of the BACE1 gene so that the formation of $\mathrm{A} \beta$ is blocked which is a future promising to treat $\mathrm{AD},{ }^{36,37}$ The previous literature by Semwal et al. ${ }^{38}$ supports that acacetin is a potent flavonoid that acts as neuroprotective, anti-inflammatory, antidiabetic, anticancer, and antimicrobial agent, also expresses inhibitory effects against acetyl- cholinesterase, cyclo-oxygenase, xanthine oxidase enzymes, glutathione reductase, and aldose reductase enzymes. ${ }^{39}$ Considering Kaempferol, a natural flavonol, ameliorates disruption of the neuronal cell membrane and mitochondria caused by oxidative stress indicates anti-oxidant properties. ${ }^{40}$ Presently, we identified acacetin, Kaempferol as potent inhibitors of APP, AChE, ADORA2A, MAOA, MAOB, APP, BACE1, and $\mathrm{BChE}$; this is also linked by $S$. rhombifolia flavonoid-rich fraction inhibited AChE enzyme as indicated by in vitro study. 
Table 5: Major phytoconstituents and AChE inhibitory activity of S. rhombifolia fractions.

\begin{tabular}{ccc}
$\begin{array}{c}\text { S. rhombifolia } \\
\text { Fractions } \\
\text { (\%yeild) }\end{array}$ & $\begin{array}{c}\text { Major phytoconstituents reported } \\
\text { in fractions }\end{array}$ & $\begin{array}{c}\text { AChE } \\
\text { inhibition }\end{array}$ \\
\hline $\begin{array}{c}\text { Pet Ether (0.3) } \\
\text { Hexane (0.56) }\end{array}$ & terpenoides, fixed oil and fats & $41.95 \pm 2.14^{*}$ \\
Chloroform & terpenoids, steroids, phytosterols & $12.87 \pm 0.64^{*}$ \\
$\mathbf{( 0 . 2 8 )}$ & alkaloids, phenols & $30.47 \pm 1.10^{*}$ \\
Ethanol (0.69) & alkaloids, terpenoids, flavonoids, & $18.96 \pm 0.96^{*}$ \\
Aqueous (0.46) & saponins, steroids, & \\
Donepezil & alkaloids, flavonoids, saponins, & $20.75 \pm 0.55^{*}$ \\
\hline
\end{tabular}

Mean \pm SEM were expressed as ${ }^{*} \mathrm{p}<0.001$ compared to Donepezil.

$\mathrm{BChE}$ is closely associated with the regulation of $\mathrm{AChE}$ levels and in $\mathrm{AD}$, this is predominantly increased which is denoted by the presence of neurofibrillary tangles and neuritic amyloid-rich plaque. ${ }^{41}$ The earlier study reports that PCR and western blot analysis revealed that the acacetin interferes with $\mathrm{A} \beta$ production by activity on BACE- 1 and APP synthesis as well as regulates the human BACE-1 and APP mRNA levels. ${ }^{42}$

Many of the flavonoids have been implicated in cognitive and neuroprotective functions through their mechanism of actions on AChE, BChE, and BACE-1 inhibitory properties by interacting with PI3-kinase/Akt and ERK signaling pathways. Alongside they also improve hippocampal neurogenesis and vascular blood flow hence; these are effective to manage AD. ${ }^{43,44}$ Sanguinine showed inhibitory activity against CHRM1 receptor along with $\mathrm{AChE}$ and $\mathrm{BChE}$ indicating its potent capability to treat $\mathrm{AD}$. As per the earlier reports, Sanguinine alkaloid obtained from many plants of the genus Narcissus belongs to the Amaryllidaceae family have Galantamine and Lycorine skeleton types and found to possess potent AChE inhibitory. ${ }^{45,46}$ Interestingly, all nine compounds namely 2D-hydroxyecdysone, Acacetin, ecdysone, kaempferol, pterosterone-3-O- $\beta$-Dglucopyranoside, Sanguinine, vascicine, vasicinol, vasicinone belongs to steroidal, flavonoid, and alkaloid class showed potent inhibitory activity against $\mathrm{AChE}$ which idealized its importance in $\mathrm{AD}$ treatment.

Furthermore, ADORA2A (Adenosine Receptor Subtype A2a) plays a crucial role in the control of synaptic plasticity and neurogenesis in the CA3 region of the hippocampus. This is also involved in NMDA-dependent synaptic transmission in the hippocampus. ADORA2A receptor inhibition can prevent $A \beta$ - induced synaptotoxicity and memory dysfunction through a p38 MAPK-dependent pathway; along with localization of microglial cells. ${ }^{47,48}$ Further, S.rhombifolia contained flavonoids acacetin and kaempferol act on the ADORA2A protein target potentially gives important clues for the treatment of AD.

S. rhombifolia enriched fractions inhibited AChE enzyme especially hexane fraction major phytoconstituents: phytosterols, steroids, and terpenoids reduce the enzyme levels which was reflected by the previous study demonstrated by Mah SH et al. ${ }^{49}$ Another recent study explored anticholinergic and antioxidant activities of S. rhombifolia hydro-ethanolic extract in cognitive deficit rats. ${ }^{10}$

\section{CONCLUSION}

Compound-gene set enrichment, network pharmacology, and docking studies of S.rhombifolia modulated pathogenic pathways associated with $A D$ via targeting major therapeutic targets such as ACHE, BCHE, APP, BACE1, ADORA2A, MAOA, MOAB by steroids (2D-hydroxyecdysone, ecdysone, pterosterone-3-O- $\beta$-D-glucopyranoside), alkaloids (sanguinine, vascicine, vasicinol, vasicinone), and flavonoids (kaempferol, acacetin) hence, reports multiple-protein targets with synergistic effects in the treatment of $\mathrm{AD}$. The in silico study data was correlated with in vitro AChE enzyme inhibition which assured to modulate major pathological pathway of AD. Furtustically, a study can be extrapolated to welldesigned wet-lab protocols that will prove the findings accordingly.

\section{ACKNOWLEDGEMENT}

We are highly thankful to KLE Academy of Higher Education and Research, College of Pharmacy, Belagaviand ICMR- National Institute of Traditional Medicine for providingnecessary support to carry out this work.

\section{CONFLICT OF INTEREST}

The authors declare no conflict of interest.

\section{ABBREVIATIONS}

AChE: Acetylcholinesterase; AD: Alzheimer's disease; ADORA2A: Adenosine A2a Receptor; APP: amyloid precursor protein; BChE: Butylcholinesterase; BE: Binding Energy; ChEBI: Chemical Entities of Biological Interest; CHRM1: Cholinergic Receptor Muscarinic 1; CHRM3: Cholinergic Receptor Muscarinic 3; DSV: Discovery Studio Visualizer; HTR2A: 5:Hydroxytryptamine Receptor 2A; IC $_{50}$ : Half:maximal inhibitory concentration; KEGG: Kyoto Encyclopedia of Genes and Genomes; NMDA: N:methyl:D:aspartate; PCR: Polymerase Chain Reaction; RCSB: Research Collaboratory for Structural Bioinformatics; PDB: Protein Data Bank; SMILES: Simplified molecular input line entry system; STRING: Search Tool for the Retrieval of Interacting Genes/Proteins; TTD: Therapeutic Data Base.

\section{REFERENCES}

1. Pattanashetti $L A$, Taranalli $A D$, Parvatrao V, Malabade $R H$, Kumar D. Evaluation of neuroprotective effect of quercetin with donepezil in scopolamine-induced amnesia in rats. Indian J Pharmacol. 2017;49(1):60-4. doi: 10.4103/0253-7613.201016 PMID 28458424

2. Folch J, Petrov D, Ettcheto M, Abad S, Sánchez-López E, García ML, et al. Current research therapeutic strategies for Alzheimer's disease treatment. Neural Plast. 2016;2016:8501693. doi: 10.1155/2016/8501693, PMID 26881137.

3. Ferri CP, Prince M, Brayne C, Brodaty $H$, Fratiglioni L, Ganguli M, et al. Global prevalence of dementia: a Delphi consensus study. Lancet. 2005;366(9503):2112-7. doi: 10.1016/S0140-6736(05)67889-0, PMID 16360788.

4. Anand R, Gill KD, Mahdi AA. Therapeutics of Alzheimer's disease: past, present and future. Neuropharmacology. 2014;76(A):27-50. doi: 10.1016/j.neuropharm 2013.07.004, PMID 23891641.

5. Haense C, Kalbe E, Herholz K, Hohmann C, Neumaier B, Krais R, Heiss WD Cholinergic system function and cognition in mild cognitive impairment. Neurobiol Aging. 2012;33(5):867-77. doi: 10.1016/j.neurobiolaging.2010.08.015, PMID 20961662.

6. Ayaz M, Junaid M, Ahmed J, Ullah F, Sadiq A, Ahmad S, et al. Phenolic contents, antioxidant and anticholinesterase potentials of crude extract, subsequent fractions and crude saponins from Polygonum hydropiper L BMC Complement Altern Med. 2014;14(1):145. doi: 10.1186/1472-6882-14-145, PMID 24884823.

7. Farnsworth N, Akerele O, Bingel A. Medicinal plants in therapy. J Ethnopharmacol. 1987;19(3):336. doi: 10.1016/0378-8741(87)90016-X.

8. Subramanya MD, Pai SR, Upadhya V, Ankad GM, Bhagwat SS, Hegde HV. Total polyphenolic contents and in vitro antioxidant properties of eight Sida species from Western Ghats, India. J Ayurveda Integr Med. 2015;6(1):24-8. doi: 10.4103/0975-9476.146544, PMID 25878460.

9. Girón LM, Freire V, Alonzo A, Cáceres A. Ethnobotanical survey of the medicinal flora used by the Caribs of Guatemala. J Ethnopharmacol. 1991;34(2-3):173-87. doi: 10.1016/0378-8741(91)90035-c, PMID 1795521.

10. Pattanashetti LA, Patil BM, Hegde HV, Kangle R. Hydroethanolic extract of Sida rhombifolia L. ameliorates scopolamine-induced cognitive dysfunction in rats. J Appl Pharm Sci. 2021;11(5):118-26.

11. Chandran U, Mehendale N, Tillu G, Patwardhan B. Network pharmacology of Ayurveda formulation Triphala with special reference to anti-cancer property. Comb Chem High Throughput Screen. 2015;18(9):846-54. doi: 10.2174/1386207 318666151019093606, PMID 26477351. 
12. Prakash A, Varma RK, Ghosal S. Alkaloid constituents of Sida acuta, S. humilis, S. rhombifolia and S. spinosa. Planta Med. 1981;43(4):384-8. doi: 10.1055/s2007-971529, PMID 17402065

13. Chaves OS, Teles YC, Monteiro MM, Mendes Junior LD, Agra MF, et al Alkaloids and phenolic compounds from Sida rhombifolia L. (Malvaceae) and vasorelaxant activity of two indoquinoline alkaloids. Molecules. 2017;22(1). doi: 10.3390/molecules22010094, PMID 28067836

14. Obah IE, Akerele JO, Obasuyi O. Antimicrobial activity of the ethanol extract of the aerial parts of Sida acuta burm.f. (malvaceae). $f$. ( malvaceae ). Trop J Pharm Res. 2007;6(4):809-13. doi: 10.4314/tjpr.v6i4.14662.

15. Chaves OS, Gomes RA, Tomaz AC, Fernandes MG, Das Graças Mendes L, et al. Secondary metabolites from Sida rhombifolia L. (Malvaceae) and the vasorelaxant activity of cryptolepinone. Molecules. 2013;18(3):2769-77. doi: 10.3390/molecules18032769, PMID 23455668

16. Patil VS, Biradar PR, Attar V, Khanal P. In silico Docking Analysis of Active Biomolecules from Cissus quadrangularis L. against PPARG. Indian J Pharm Educ Res. 2019;53(3s):s332-7. doi: 10.5530/ijper.53.3s.103.

17. Zeng $Q$, Li L, Jin $Y$, Chen $Z$, Duan $L, C a o ~ M$, et al. A network pharmacology approach to reveal the underlying mechanisms of Paeonia lactiflora Pall. On the treatment of Alzheimer's disease. Evid Based Complement Alternat Med. 2019:2019:8706589. doi: 10.1155/2019/8706589, PMID 31827565.

18. Khanal P, Patil BM. Gene set enrichment analysis of alpha-glucosidase inhibitors from Ficus benghalensis. Asian Pac J Trop Biomed. 2019;9(6):263-70. doi: 10.4103/2221-1691.260399.

19. Forli S, Huey R, Pique ME, Sanner MF, Goodsell DS, Olson AJ. Computational protein-ligand docking and virtual drug screening with the AutoDock suite. Nat Protoc. 2016;11(5):905-19. doi: 10.1038/nprot.2016.051, PMID 27077332.

20. Cos P, Vlietinck AJ, Vanden Berghe DV, Maes L. Anti-infective potential of natural products: how to develop a stronger in vitro "proof-of-concept." J Ethnopharmacol. 2006;106(3):290-302. doi: 10.1016/j.jep.2006.04.003, PMID 16698208.

21. Dhanasekaran S, Perumal P, Palayan M. In-vitro Screening for Acetylcholinesterase enzyme Inhibition potential and Antioxidant Activity of Extracts of Ipomoea Aquatica Forsk: therapeutic lead for Alzheimer's disease. J App Pharm Sci. 2015;5(2):012-6. doi: 10.7324/JAPS.2015.50203.

22. Anooj ES, Amrutha TM, Charumathy M, Gangadhar L. Quantitative and Qualitative identification of Phytochemical Constituents of Sida rhombifolia leaves extract. ijrte. 2019;8(2S4):403-8. doi: 10.35940/ijrte.B1078.0782S419.

23. Tanumihadja M, Mattulada IK, Natsir N, Subehan S, Mandey F, Muslimin L. Structural assessment of chemical constituent of Sidaguri (Sida rhombifolia linn) and its ability to inhibit cyclooxygenase. Pesqui Bras Odontopediatria Clín. Integr. 2019;19(1):1-7. doi: 10.4034/PBOCI.2019.191.96.

24. Jadhav AN, Pawar RS, Avula B, Khan IA. Ecdysteroid glycosides from Sida rhombifolia L. Chem Biodivers. 2007;4(9):2225-30. doi: 10.1002/cbdv.200790180, PMID 17886841.

25. Abat JK, Kumar S, Mohanty A. Ethnomedicinal, Phytochemical and ethnopharmacological aspects of four medicinal plants of Malvaceae Used in Indian traditional medicines: a review. Medicines (Basel). 2017;4(4):75. doi: 10.3390/ medicines4040075, PMID 29057840.

26. Pan SY, Zhou SF, Gao SH, Yu ZL, Zhang SF, Tang MK, et al. New perspectives on how to discover drugs from herbal medicines: CAM's outstanding contribution to Modern Therapeutics. Evid Based Complement Alternat Med. 2013;2013:627375. doi: 10.1155/2013/627375, PMID 23634172

27. Vitali F, Mulas F, Marini P, Bellazzi R. Network-based target ranking for polypharmacological therapies. J Biomed Inform. 2013;46(5):876-81. doi: 10.1016/j.jbi.2013.06.015, PMID 23850841.

28. Lagunin AA, Ivanov SM, Gloriozova TA, Pogodin PV, Filimonov DA, Kumar S, et al. Combined network pharmacology and virtual reverse pharmacology approaches for identification of potential targets to treat vascular dementia [sci rep:257]. Sci Rep. 2020;10(1):257. doi: 10.1038/s41598-019-57199-9, PMID 31937840.

29. Zhao J, Deng Y, Jiang Z, Qing H. G protein-coupled receptors (GPCRs) in Alzheimer's disease: A focus on BACE1 related GPCRs. Front Aging Neurosci. 2016;8:1-15

30. Liu JF, Hu AN, Zan JF, Wang P, You QY, Tan AH. Network Pharmacology deciphering mechanisms of volatiles of Wendan granule for the treatment of Alzheimer's disease. Evid Based ComplementAlternat Med. 2019;2019:7826769. doi: 10.1155/2019/7826769, PMID 30891080

31. Kandimalla $\mathrm{R}$, Reddy $\mathrm{PH}$. Therapeutics of neurotransmitters in Alzheimer's disease. J Alzheimers Dis. 2017;57(4):1049-69. doi: 10.3233/JAD-161118, PMID
28211810

32. Borbély É, Payrits M, Hunyady Á, Mezo G, Pintér E. Important regulatory function of transient receptor potential ankyrin 1 receptors in age-related learning and memory alterations of mice. Geroscience. 2019;41(5):643-54. doi: 10.1007/ s11357-019-00083-1, PMID 31327098

33. Tong BCK, Wu AJ, Li M, Cheung KH. Calcium signaling in Alzheimer's disease and therapies. Biochim Biophys Acta Mol Cell Res. 2018;1865(11 Pt B):1745-60. doi: 10.1016/j.bbamcr.2018.07.018, PMID 30059692.

34. Koulakoff A, Mei X, Orellana JA, Sáez JC, Giaume C. Glial connexin expression and function in the context of Alzheimer's disease. Biochim Biophys Acta. 2012;1818(8):2048-57. doi: 10.1016/j.bbamem.2011.10.001, PMID 22008509.

35. Yi C, Koulakoff A, Giaume C. Astroglial connexins as a therapeutic target for Alzheimer's disease. Curr Pharm Des. 2017;23(33):4958-68. doi: 10.2174/13816 12823666171004151215 , PMID 28982320.

36. Das B, Yan R. Role of BACE1 in Alzheimer's synaptic function. Transl Neurodegener. 2017;6:23. doi: 10.1186/s40035-017-0093-5, PMID 28855981.

37. Vassar R. BACE1: The $\beta$-secretase enzyme in Alzheimer's disease. J Mol Neurosci. 23(1-2):105-14. doi: 10.1385/JMN:23:1-2:105.

38. Semwal RB, Semwal DK, Combrinck S, Trill J, Gibbons S, Viljoen A. Acacetin-A simple flavone exhibiting diverse pharmacological activities. Phytochem Lett. 2019;32:56-65. doi: 10.1016/j.phytol.2019.04.021.

39. Hussain G, Zhang L, Rasul A, Anwar H, Sohail MU, Razzaq A, et al. Role of plant-derived flavonoids and their mechanism in attenuation of Alzheimer's and Parkinson's diseases: an update of recent data. Molecules. 2018;23(4):814. doi: 10.3390/molecules23040814, PMID 29614843.

40. Kouhestani S, Jafari A, Babaei P. Kaempferol attenuates cognitive deficit via regulating oxidative stress and neuroinflammation in an ovariectomized rat model of sporadic dementia. Neural Regen Res. 2018;13(10):1827-32. doi: 10.4103/1673-5374.238714, PMID 30136699.

41. Greig NH, Utsuki T, Ingram DK, Wang Y, Pepeu G, Scali C, et al. Selective butyrylcholinesterase inhibition elevates brain acetylcholine, augments learning and lowers Alzheimer beta-amyloid peptide in rodent. Proc Natl Acad Sci U S A. 2005;102(47):17213-8. doi: 10.1073/pnas.0508575102, PMID 16275899.

42. Bu J, Shi S, Wang HQ, Niu XS, Zhao ZF, Wu WD, et al. Acacetin protects against cerebral ischemia-reperfusion injury via the NLRP3 signaling pathway. Neural Regen Res. 2019;14(4):605-12. doi: 10.4103/1673-5374.247465, PMID 30632500.

43. Ayaz M, Sadiq A, Junaid M, Ullah F, Ovais M, Ullah I, et al. Flavonoids as prospective neuroprotectants and their therapeutic propensity in aging associated neurological disorders. Front Aging Neurosci. 2019;11:155. doi: 10.3389/ fnagi.2019.00155, PMID 31293414.

44. Mansuri ML, Parihar P, Solanki I, Parihar MS. Flavonoids in modulation of cell survival signalling pathways. Genes Nutr. 2014;9(3):400. doi: 10.1007/s12263014-0400-z, PMID 24682883.

45. López S, Bastida J, Viladomat F, Codina C. Acetylcholinesterase inhibitory activity of some Amaryllidaceae alkaloids and Narcissus extracts. Life Sci. 2002;71(21):2521-9. doi: 10.1016/s0024-3205(02)02034-9, PMID 12270757.

46. Bastida J, Lavilla R, Viladomat F. Chemical and biological aspects of Narcissus alkaloids. Alkaloids Chem Biol. 2006;63:87-179. doi: 10.1016/s10994831(06)63003-4, PMID 17133715.

47. Canas PM, Porciúncula LO, Cunha GMA, Silva CG, Machado NJ, Oliveira JM, et al. Adenosine A2a receptor blockade prevents synaptotoxicity and memory dysfunction caused by $\beta$-amyloid peptides via p38 mitogen-activated protein kinase pathway. J Neurosci. 2009;29(47):14741-51. doi: 10.1523/JNEUROSCI. 3728-09.2009, PMID 19940169.

48. Lopes CR, Cunha RA, Agostinho P. Astrocytes and adenosine A2A receptors: active players in Alzheimer's disease. Front Neurosci. 2021;15:666710. doi: 10.3389/fnins.2021.666710.

49. Mah SH, Teh SS, Ee GCL. Anti-inflammatory, anti-cholinergic and cytotoxic effects of Sida rhombifolia. Pharm Biol. 2017;55(1):920-8. doi: 10.1080/ 13880209.2017.1285322, PMID 28152649.

Article History: Received: 30-07-2021; Revised: 08-08-2021; Accepted: 28-08-2021.

Cite this article: Pattanashetti L, Patil BM, Hegde HV. In silico and in vitro Approach To Identify Memory Enhancers from Sida rhombifolia L. J Young Pharm. 2021;13(4):363-9. 